\title{
Agôn
}

Revue des arts de la scène

Critiques | Saison 2016-2017

\section{Avignon, 14 juillet : Sopro, texte et mise en scène de Tiago Rodrigues}

Du travail théâtral

\section{Caroline Châtelet}

\section{CpenEdition}

Journals

Édition électronique

URL : http://journals.openedition.org/agon/4028

DOI : 10.4000 /agon.4028

ISSN : 1961-8581

Éditeur

Association Agôn

Référence électronique

Caroline Châtelet, "Avignon, 14 juillet : Sopro, texte et mise en scène de Tiago Rodrigues », Agôn [En ligne], Critiques, mis en ligne le 13 juillet 2017, consulté le 23 septembre 2020. URL : http://

journals.openedition.org/agon/4028; DOI : https://doi.org/10.4000/agon.4028

Ce document a été généré automatiquement le 23 septembre 2020.

Association Agôn et les auteurs des articles 


\section{Avignon, 14 juillet : Sopro, texte et mise en scène de Tiago Rodrigues}

Du travail théâtral

Caroline Châtelet

\section{RÉFÉRENCE}

Sopro - texte et mise en scène de Tiago Rodrigues, du 7 au 16 juillet au Cloître des Carmes

1 Découvrant Sopro, nouvelle création du metteur en scène Tiago Rodrigues, c'est la citation de Xavier Douroux évoquée quelques jours auparavant - en introduction de l'article sur Antigone $e^{1}$ monté par Satoshi Miyagi - qui m'est revenue en mémoire. [Allez, comme celle-ci ${ }^{2}$ est passionnante par la réflexion qu'elle ouvre, je la remets : «Je crois beaucoup aux spectres des cuvres dans les expositions. Au fait qu'une cuvre, pour peu qu'elle ait eu un vrai rapport avec une salle, continue à la hanter. Tout cela est très lié à la mémoire (...) »] Cette position du co-fondateur et co-directeur du Centre d'art Le Consortium à Dijon permettait d'évoquer 1) le faible et rare intérêt du théâtre pour les questions de la trace, des spectres des œuvres ; 2) l'interrogation, elle, plus fréquente, portant sur la pertinence d'un projet dans un lieu donné.

2 Et puis, voilà, devant Sopro, cette phrase a resurgi. Avec la certitude que c'est notamment cette idée - les lieux gardent la mémoire des œuvres qui s'y produisent que Tiago Rodrigues met au travail avec son équipe. La présence des spectres est matérialisée durant tout le spectacle par une lumière blanche venue du sol : devenant pour Sopro la scène d'un théâtre en friche, la scène du Cloître des Carmes irradie par son plancher de bois. Il y a cette évocation-là, visible, et il y a ses multiples ramifications, que le spectacle va progressivement déplier : qu'est-ce qu'une trace, un souvenir? Comment se fabrique une mémoire? Qu'est-ce que le temps laisse, transforme, permet d'oublier, ou au contraire empêche de cicatriser? Ces questionnements, le comédien, auteur et metteur en scène portugais les aborde sous 
l'angle du travail et les déroule par le biais de l'intime. Soit, par les confidences de Cristina Vidal, souffleuse au Teatro Nacional Dona Maria II depuis 1978. Comme c'est son métier qui vaut à Cristina Vidal d'avoir rencontré Tiago Rodrigues en 2010, lorsque l'artiste est invité à travailler au théâtre (il en est depuis devenu le directeur), comme c'est son métier - voué à la disparition - qui a motivé la création de Sopro, c'est par le travail que le spectacle se déploie. Pendant que les derniers spectateurs prennent place, Cristina Vidal entre sur scène. Vêtue de noir, armée d'un chronomètre et de textes, elle arpente le plateau dans l'attente de l'arrivée des comédiens - puisque les spectateurs l'apprendront plus tard, elle arrive toujours la première au théâtre. Mais si la femme vient évoquer, à l'aide des acteurs, sa profession, elle va ici l'excéder : à mi-chemin entre la souffleuse et la metteuse en scène, elle appelle les comédiens, leur attribue leurs places, leurs rôles, les scènes à jouer. Ces indications sont données dans un perpétuel murmure, rappelant que si Cristina Vidal a accepté de sortir de l'ombre, elle n'abandonne pas sa profession pour autant. De sa première venue au théâtre en tant que spectatrice - enfant, elle fût cachée dans le trou du souffleur - à son premier jour de travail, des accidents pendant les spectacles au quotidien de l'institution, ce sont les coulisses d'une institution théâtrale que les comédiens et Cristina Vidal racontent. Pour autant, Sopro dépasse le seul anecdotique et l'entre-soi. À travers cette mémoire, ce sont des vies entières consacrées à un art, au travail du théâtre qui se racontent. Il y a les maladies, les amours, les séparations, les morts, les deuils, la sédimentation des œuvres, les résonances entre l'art et la vie, la baisse des financements publics, les difficultés de plus en plus grandes à continuer à exercer cet art. Avec finesse, intelligence et pudeur, Sopro raconte comment le théâtre, le travail théâtral façonne un imaginaire, construit une perception du monde, oriente des vies. Mais si le théâtre est au centre de ses existences-là, il n'en demeure pas moins fragile, minoritaire, en danger et c'est dans un théâtre abandonné, envahi par les herbes folles, que Cristina Vidal a souhaité voir le spectacle se dérouler. La menace existe et les fermetures pourraient arriver. Elles arrivent d'ailleurs, même si en France on préfère fusionner les théâtres plutôt que de les fermer (façon ô combien subtile de noyer le poisson et d'éteindre toute velléité de revendications).

3 Nonobstant une tendance, à la fin du spectacle, de l'auteur Tiago Rodrigues à se révéler trop complaisant à son propre égard, Sopro dessine avec brio, virtuosité, délicatesse et une attention renouvelée à tous les interprètes présents sur scène, un portrait du théâtre et de ses spectres. Il rappelle aussi, avec sa scène finale construite comme un geste de réparation, la puissance et la force de cet art.

4 Au sujet de ce spectacle, la journaliste de l'AFP Marie-Pierre Vernay évoquait La Nuit américaine, de François Truffaut. Ce film m'est, comme à elle, venu à l'esprit par sa parole sur le travail, l'art et la vie, notamment dans l'adresse de François Truffaut (jouant le réalisateur) à Jean-Pierre Léaud (incarnant Alphonse, jeune comédien en proie aux doutes) : «Ne fais pas l'idiot Alphonse, tu es un très bon acteur. Le travail marche bien. Je sais, il y a la vie privée, mais la vie privée, elle est boiteuse pour tout le monde. Les films sont plus harmonieux que la vie Alphonse, il n'y a pas d'embouteillage dans les films, il n'y a pas de temps mort. Les films avancent comme des trains, tu comprends? Comme des trains dans la nuit. Les gens comme toi, comme moi, tu le sais bien, on est faits pour être heureux dans le travail, dans notre travail de cinéma. Salut Alphonse, je compte sur toi. » 


\section{NOTES}

1. http://journals.openedition.org/agon/4036

2. https://issuu.com/media.pop/docs/novo_16/56 